\title{
Numerical study of laminar fully developed non-Newtonian liquid flow in rough circular microchannel
}

\author{
Manish Vashishtha*, Jay Thakkar \\ Malaviya National Institute of Technology, Department of Chemical Engineering, JLN Marg, Jaipur -302017, India \\ "Corresponding author: mvche.mnit@gmail.com
}

\begin{abstract}
The present study aims to unveil the characteristics of fully developed laminar, incompressible, pressure driven non-Newtonian liquid flow in rough circular microchannels. In the present analysis Gaussian isotropic roughness distribution in circular microchannel is considered. The effect of varying surface wall roughness and flow behavior index has been studied numerically for both the pseudo plastic and dilatant fluids. It is found out that while increasing the relative roughness for a particular flow behavior index, the frictional resistance to flow in the microchannel increases and the effect is more pronounced in the case of pseudo plastic fluids. In the case of a pseudo plastic liquid flow for a constant relative surface wall roughness, on decreasing the value of flow behavior index below 1, the frictional resistance to the flow in the channel increases. While in the case of dilatant fluids with increasing the value of flow behavior index from 1 and above for a constant relative surface wall roughness the frictional resistance to the flow in the channel decreases.
\end{abstract}

Keywords: Power law, non-Newtonian fluid, roughness, microchannel.

\section{INTRODUCTION}

According to $\mathrm{Obot}^{1}$, microchannels can be defined as the channels whose characteristic dimensions are less than $1 \mathrm{~mm}$. Microchannels are becoming increasingly useful in various research fields in today's nano and micro fascinated world. They find applications in heat exchangers, reactors, etc. Microchannel heat exchangers can remove high heat fluxes as they have high specific characteristics such as high surface area per unit volume and high heat transfer coefficient and thus they are used widely in cooling applications ${ }^{2}$.

In the present paper the flow behavior of the non-Newtonian incompressible liquid fluids through rough circular microchannels is closely looked at. Urbanek et al. $^{3}$ studied experimentally the flow of 1,2-propanol and 1,3-pentanol in silicon microchannels with hydraulic diameters of 12 and $25 \mu \mathrm{m}$ and found out that the Poiseuille number depends on the temperature and also probably on the molecular isomerism of the liquid. The Poiseuille number increases by $25 \%$ for $12 \mu \mathrm{m}$ channel while it increases by $10 \%$ for $25 \mu \mathrm{m}$ channel as the temperature varies between $0^{\circ} \mathrm{C}$ to $85^{\circ} \mathrm{C}$. Mala and $\mathrm{Li}^{4}$ studied experimentally the flow of deionized water at the low Reynolds number through stainless steel and fused silica microchannels with the diameters of 50-254 $\mu \mathrm{m}$ and the relative roughness of $0.69-3.5 \%$. The experimental results were greater than those predicted by the conventional theory and the deviation increased with decreasing the diameter and increasing the Reynolds number. Celata et al. ${ }^{5}$ studied experimentally the flow of R114 in a stainless steel microchannel having the diameter of $130 \mu \mathrm{m}$ and the relative surface roughness of $2.65 \%$ for a wide range of the Reynolds numbers between 100 and 8000 . In their experimental study, they showed that the transition from laminar to turbulent flow occurs when the Reynolds number is in the range of 1880-2480. Brutin and Tadrist ${ }^{6}$ studied experimentally water flow in the fused silicon microchannels with the diameter ranging between 50 to $530 \mu \mathrm{m}$ and the relative roughness less than $0.02 \%$.
On decreasing the channel diameter the friction factor increased and was maximum for the channel of the 50 $\mu \mathrm{m}$ diameter. $\mathrm{Li}$ et al. ${ }^{7}$ studied deionized water flow in glass microchannels, silicon microchannels and stainless steel microchannels with the diameters ranging between 79.9-166.3 $\mu \mathrm{m}, 100.25-205.3 \mu \mathrm{m}$ and 128.76-179.8 $\mu \mathrm{m}$ respectively with the Reynolds number less than 4000 . Li et $\mathrm{al}^{7}$ found that the product of the Darcy friction factor and the Reynolds number for glass and silicon microchannels was in good agreement with the classical theoretical predictions but was $15-37 \%$ higher in the case of stainless steel microchannels having higher relative roughness in the range of 3\%-4\%. Phares and Smedley ${ }^{8}$ used deionized water, tap water, saline solution and glyce$\mathrm{rol} /$ water mixture to study the flow in four stainless steel channels with the diameters varying between 164-440 $\mu \mathrm{m}$ and the relative surface roughness between 1.8-2.5\% and two polyimide channels having diameters of 119 and 152 $\mu \mathrm{m}$ and having relative surface roughness less than $1 \%$. Kandlikar et al. ${ }^{9}$ investigated the effect of roughness on pressure drop and heat transfer in rough microchannels. The roughness of the inside surface of the channel is changed by etching it with an acid solution. They found that for larger channels (channel diameter $=1.067 \mathrm{~mm}$ and Reynolds number between 500-2600) the effect of varying the roughness is insignificant but becomes more pronounced for smaller channels (channel diameter $=$ $0.62 \mathrm{~mm}$ and Reynolds number between 900-3000). Tang et al. ${ }^{10}$ investigated the effect of compressibility, roughness and rarefaction influences on the flow characteristics of nitrogen and helium in stainless steel channels and fused silica channels of various diameters. A.J. Ghajar et al. ${ }^{11}$ studied experimentally the friction factor in the transition region for water flow in mini and micro channels. T. Engin et al. ${ }^{12}$ studied the effect of wall roughness on the laminar flow of Bingham plastic fluids through microchannels. Bahrami et al. ${ }^{13}$ studied the effect of wall roughness on pressure drop in rough circular microchannels for the flow of Newtonian fluids. The values predicted by the new model which they ${ }^{13}$ developed are 
in good agreement with the experimental data of many other researchers. G.H. Tang ${ }^{\mathbf{1 4}}$ studied experimentally the flow of deionized water and polyacrylamide (PAM) solution, a non-Newtonian liquid fluid in microchannels over a wide range of Reynolds numbers in fused silica microchannels, fused silica square microchannels and stainless steel microchannels with the diameters ranging between $75-250 \mu \mathrm{m}$, equivalent diameters of $75-100$ $\mu \mathrm{m}$ and $120-300 \mu \mathrm{m}$ respectively. They found out that for deionized water no deviation of friction factors was observed from the theoretical prediction but for PAM solution the friction factors were much higher than the conventional theoretical predictions.

There is a need for a better understanding of the effect of wall roughness on non-Newtonian liquid flow characteristics in circular microchannels. The wall roughness effects on the flow of non-Newtonian fluids in circular microchannels have not been studied extensively. The present work is an attempt to fill this gap in the developing area of flow in microchannels.

\section{FRICTIONAL RESISTANCE FOR SMOOTH CIRCU- LAR MICROCHANNELS}

The liquid flowing in the circular microchannel considered in the present analysis is taken as the non-Newtonian power law liquid. According to the Ostwald de Waele equation representing the rheological behavior governing power law fluid ${ }^{\mathbf{1 5}}$,

$\tau=k\left(\frac{d u}{d r}\right)^{n}$

Where, $k$ and $n$ are constants called flow consistency index and the flow behavior index respectively. $\tau$, is the shear force. For pseudo plastic fluids (i.e. shear thinning fluids), $n<1$ and for dilatant fluids (shear thickening fluids), $n>1$. The above equation (1) reduces to the constitutive equation of Newtonian fluid for $n=1$ and $k=\mu$. For the fluids following the power law model the velocity variation with the local radius can be expressed according to the conventional theory as ${ }^{\mathbf{1 5}}$,

$v=\frac{\left(\Delta P^{\frac{1}{n}}\right)\left(R^{\left(\frac{1}{n}+1\right)}-r_{1}^{\left(\frac{1}{n}+1\right)}\right)}{(2 k L)^{\frac{1}{n}}\left(\frac{1}{n}+1\right)}$

Here, $R$ is the radius of the channel while, $r_{1}$ is the local radius. The average velocity can then be expressed according to the following equation,

$\bar{v}=\left(\frac{\Delta P}{2 k L}\right)^{\frac{1}{n}}\left(R^{\left(\frac{1}{n}+1\right)}\right)\left(\frac{n}{3 n+1}\right)$

The mass flow rate $(\dot{m})$ of the non-Newtonian fluid in the microchannel can be defined as,

$\dot{m}=\pi \rho\left(\frac{\Delta P}{2 k L}\right)^{\frac{1}{n}}\left(R^{\left(\frac{1}{n}+3\right)}\right)\left(\frac{n}{3 n+1}\right)$

The fluid moves under the influence of the pressure gradient in the direction of the flow in microchannel. The Reynolds number associated with the flow is generally small, the flow is usually laminar and the velocity varies across the entire cross-sectional area of the channel.
Also the end effects have been neglected. Assuming the electrical network analogy, a frictional resistance can be expressed as ${ }^{\mathbf{1 3}}$ :

$\dot{m}=\frac{\Delta P}{R_{f, 0}}$

Here, $R_{f, 0}$ is the frictional resistance of circular microchannel of length $L>>$.

The assumptions in the development of the present model on circular microchannel are:

1) Fully developed laminar and non-Newtonian liquid flow is considered.

2) The walls of the microchannel are rough with the roughness assumed to be Gaussian. The roughness is assumed to be isotropic in all directions.

3) Rarefaction, compressibility, and slip-on-wall effects are negligible.

4) Fluid properties like temperature, viscosity, density are assumed to be constant.

Combining the equations (4) and (5) gives,

$$
R_{f, 0}=\frac{\Delta P}{\pi \rho\left(\frac{\Delta P}{2 k L}\right)^{\frac{1}{n}}\left(R^{\left(\frac{1}{n}+3\right)}\right)\left(\frac{n}{3 n+1}\right)}=\frac{\Delta P}{\pi R^{2} \rho \bar{v}}
$$

The fanning friction factor $f$, according to conventional theory is defined as,

$f=\frac{(\Delta P) R}{L \rho\left(\bar{v}^{2}\right)}$

By using the equations (6) and (7), $R_{f, 0}$ can be linked to fanning friction factor as below,

$f=\frac{\pi R^{3}}{\bar{v} L} R_{f, 0}$

\section{FRICTIONAL RESISTANCE FOR ROUGH CIRCULAR MICROCHANNEL}

According to Bahrami et al. ${ }^{\mathbf{1 3}}$ roughness or the unevenness of the surface can be thought of as the surface deviation from the nominal topography. When this unevenness is isotropic and randomly distributed over the surface, such a distribution of surface roughness is known as Gaussian distribution. As the wall roughness in the present model is assumed to be random, a precise value of the radius, $R$, cannot be evaluated and used. Hence a new local radius, $r$ is needed, which takes into account the probabilities of occurring of different local radii occurring because of the random nature of the wall roughness. As shown in Fig. 1, the wall roughness of the microchannel is assumed to posses a Gaussian distribution in the angular direction.

The wall roughness at the same time also varies in the longitudinal direction along the length of the tube with the same Gaussian distribution but a different random variable as shown in the Fig. 2.

The random variables, $\varphi$ and $\omega$, are used to represent the deviations of the local radius, $r$ in the angular direction and longitudinal direction respectively. The standard deviation of, $\varphi$ and $\omega$ is the wall roughness, $\sigma_{\theta}$ and $\sigma_{x}$ respectively with the following Gaussian distribution ${ }^{13}$, 


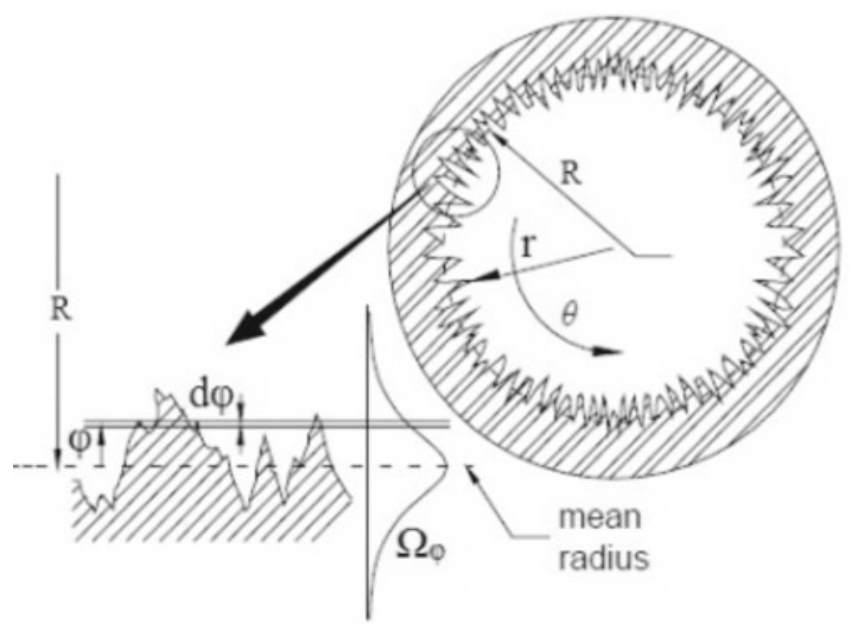

Figure 1. Angular Gaussian distribution of the rough circular microchannel ${ }^{13}$

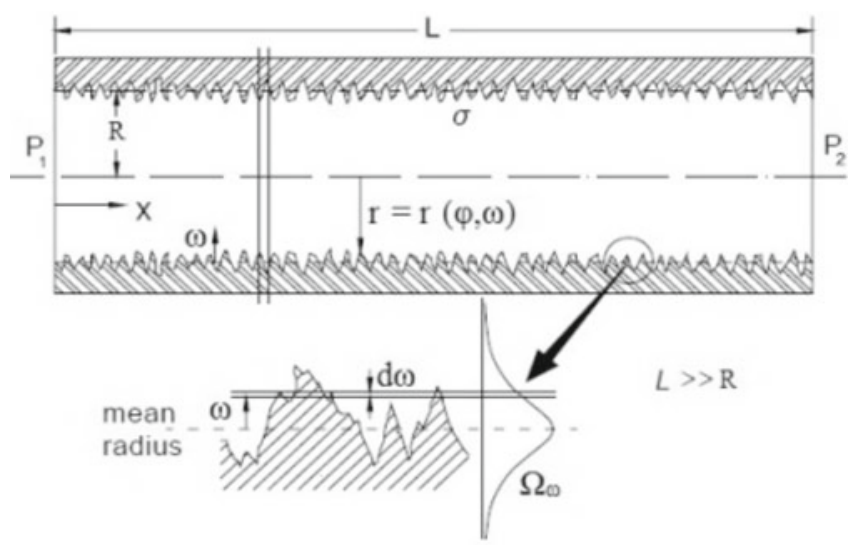

Figure 2. Longitudinal Gaussian distribution of the rough circular microchannel ${ }^{13}$

$\Omega_{\varphi}=\frac{\exp \left(\frac{-\varphi^{2}}{2 \sigma_{\theta}{ }^{2}}\right)}{\sqrt{2 \pi} \sigma_{\theta}}$

$\Omega_{\omega}=\frac{\exp \left(\frac{-\omega^{2}}{2 \sigma_{x}^{2}}\right)}{\sqrt{2 \pi} \sigma_{x}}$

The local radius can be taken as a superposition of two random variables one varying in the angular direction while the other varying in the longitudinal direction. Therefore, the local radius can be written as, $r=R+$ $\varphi+\omega$. The local radius, $r$ can vary over a wide range of values from much larger to much smaller length as compared to the radius, $R$. As the present study uses isotropic roughness it can be assumed that, $\sigma_{\theta}=\sigma_{x}=\sigma$, but in the general case this is not true and both standard deviations can be different. By the use of equation (6), the frictional resistance for rough microchannel can be written as,

$$
R_{f, \text { rough }}=\frac{\Delta P}{\pi \rho\left(\frac{\Delta P}{2 k L}\right)^{\frac{1}{n}}\left(\frac{n}{3 n+1}\right)} \int_{-\infty}^{\infty} \int_{-\infty}^{\infty} \frac{\Omega_{\varphi} \Omega_{\omega}}{r^{\left(3+\frac{1}{n}\right)}} d \varphi \cdot d \omega
$$

By the use of equation (9-10) and substituting, $u=\frac{\varphi}{\sigma}$ and $v=\frac{\omega}{\sigma}$ equation (11) can be modified as,

$R_{f, \text { rough }}=\frac{1}{2 \pi}\left(\frac{\Delta P}{\pi \rho\left(\frac{\Delta P}{2 k L}\right)^{\frac{1}{n}}\left(\frac{n}{3 n+1}\right)}\right) \int_{-\infty}^{\infty} \int_{-\infty}^{\infty} \frac{\exp \left(-\frac{u^{2}}{2}\right) \cdot \exp \left(-\frac{v^{2}}{2}\right)}{r^{\left(3+\frac{1}{n}\right)}} d u \cdot d v$

Substituting the value of local radius $r$, in the above equation and taking the term of radius $R$ common from the equation and then substituting, $\phi=\frac{\sigma}{R}$ the following equation is obtained,

$R_{f, \text { ovoug }}=\frac{1}{2 \pi}\left(\frac{\Delta P}{\pi \rho\left(\frac{\Delta P}{2 k L}\right)\left(\frac{n}{n}\left(\frac{n}{3 n+1}\right)\left(R^{\left(3+\frac{1}{n}\right)}\right)\right.}\right) \int_{-\infty}^{\infty} \infty_{-\infty}^{\infty} \frac{\exp \left(-\frac{u^{2}}{2}\right) \cdot \exp \left(-\frac{v^{2}}{2}\right)}{\left.(1+\phi(u+v))^{3+\frac{1}{n}}\right)} d u \cdot d v$

In the above equation, $\varphi$ is the relative wall roughness. It should be noted here that in the present model of rough circular microchannel, the relative roughness is defined as the wall roughness over the channel radius, $R$ and not the conventional relative roughness defined over the diameter of the microchannel. The normalized frictional resistance which is the ratio of the frictional resistance of rough microchannel and smooth microchannel is defined as,

$R_{f}^{*}=\frac{R_{f, \text { rough }}}{R_{f, 0}}=$ normalized frictional resistance $=$

$\frac{1}{2 \pi}\left(\int_{-\infty}^{\infty} \int_{-\infty}^{\infty} \frac{\exp \left(-\frac{u^{2}}{2}\right) \cdot \exp \left(-\frac{v^{2}}{2}\right)}{(1+\phi(u+v))^{\left(3+\frac{1}{n}\right)}} d u \cdot d v\right)$

From the equation (8) it is observed that the fanning friction factor varies directly as the frictional resistance of the channel, and hence the effect of wall roughness on the fanning friction factor $f$, is the same as that of frictional resistance. In other words it can be assumed that,

$f^{*}=\frac{f_{\text {rough }}}{f_{0}}=R_{f}^{*}=\frac{R_{f, \text { rough }}}{R_{f, 0}}$

Now the above equation (14) can be used to calculate the friction factor for rough channel.

\section{RESULTS AND DISCUSSIONS}

The double integral in equation (13) is solved numerically over a range of relative roughness and flow behavior index to evaluate the value of frictional resistance offered by the rough circular microchannel. After evaluating the value of frictional resistance, the normalized frictional resistance is evaluated by the use of equation (14). It is found out that the surface wall roughness also affects the flow of the non-Newtonian fluids in the laminar region. This effect is studied for the varying flow behavior index from 0.095 to 20 . The relative roughness is varied from 0 to $9 \%$ in the case of dilatant fluid and from 0 to $7 \%$ in the case of the 
pseudo plastic fluid. Table 1, below shows the effect of relative roughness and the flow behavior index on the pseudo plastic fluids. The index is varied from 0.095 to 1 and the roughness is varied up to $7 \%$. It is observed from the table that on increasing the relative roughness, the normalized frictional resistance increases for a particular flow behavior index, $n$. Also, for a particular relative roughness it is observed that on decreasing the flow behavior index, the normalized frictional resistance increases. The effect of relative roughness is more pronounced for the flow behavior index less than 0.1 and increases drastically for the fluids whose values of $n$ is closer to zero. For the relative surface roughness values greater than $7 \%$ the corresponding column in the table can be extrapolated to get the corresponding value of the normalized friction factor for a particular flow behavior index.

The above effect can also be observed from Fig. 3-4. For clear representation of the results fewer values of index, $n$ and relative roughness have been taken in these Figures.

For dilatant fluids it is observed from Table 2 below that on increasing the relative roughness for a constant flow behavior index the normalized frictional resistance increases but the effect of increasing the flow behavior index results in the decrease in the normalized frictional resistance for a particular roughness value. The effect of relative roughness is less pronounced on dilatant fluids than on pseudo plastic fluids. Further values of normalized friction factors for surface roughness greater than $9 \%$ can be found by extrapolation of the table for corresponding value of flow behavior index.

The effect observed above is depicted in Fig. 5-6 below. Fewer values of the flow behavior index and relative roughness have been plotted to simplify the graph.

Thus, as we go on increasing the value of the flow behavior index for a constant relative surface roughness value, the frictional resistance decreases and reaches its minimum value when $n$, approaches infinity.

\section{COMPARISON WITH EXPERIMENTAL DATA}

Tang et al. ${ }^{14}$ in their recent work studied experimentally the flow of the non-Newtonian fluid, polyacrylamide (PAM) in rough stainless steel circular microchannels having diameters $120 \mu \mathrm{m}, 170 \mu \mathrm{m}, 260 \mu \mathrm{m}$ and $300 \mu \mathrm{m}$. The length of the channels taken was $100 \mathrm{~mm}$ and temperature of $15.9^{\circ} \mathrm{C}$. The value of $k$ and $n$ for PAM at this temperature are 0.00799 and 0.8073 respectively. The measured roughness values of the channels are

Table 1. Relative Roughness, $\varphi$ v/s Power Law Index, $\mathrm{n}<1 \mathrm{v} / \mathrm{s}$ Normalized frictional resistance, $R_{f}^{*}$

\begin{tabular}{|c|c|c|c|c|c|c|c|c|}
\hline$\phi$ & 0 & 0.010 & 0.020 & 0.030 & 0.040 & 0.050 & 0.060 & 0.070 \\
\hline $\mathrm{n}$ & $R_{f}{ }^{*}$ & $R_{f}{ }^{*}$ & $R_{f}{ }^{*}$ & $R_{f}{ }^{*}$ & $R_{f}{ }^{*}$ & $R_{f}{ }^{*}$ & $R_{f}{ }^{{ }^{*}}$ & $R_{f}{ }^{{ }^{*}}$ \\
\hline 0.095 & 1 & 1.01990 & 1.08281 & 1.19944 & 1.39221 & 1.70550 & 2.23187 & 3.06000 \\
\hline 0.1 & 1 & 1.01842 & 1.07644 & 1.18327 & 1.35786 & 1.63706 & 2.09546 & 2.88000 \\
\hline 0.2 & 1 & 1.00724 & 1.02945 & 1.06816 & 1.12626 & 1.20846 & 1.32239 & 1.48066 \\
\hline 0.3 & 1 & 1.00466 & 1.01887 & 1.04332 & 1.07924 & 1.12863 & 1.19448 & 1.28138 \\
\hline 0.4 & 1 & 1.00359 & 1.01448 & 1.03313 & 1.06028 & 1.09715 & 1.14550 & 1.20797 \\
\hline 0.5 & 1 & 1.00301 & 1.01214 & 1.02770 & 1.05026 & 1.08068 & 1.12022 & 1.17072 \\
\hline 0.6 & 1 & 1.00265 & 1.01069 & 1.02436 & 1.04412 & 1.07065 & 1.10495 & 1.14843 \\
\hline 0.7 & 1 & 1.00241 & 1.00971 & 1.02211 & 1.04000 & 1.06395 & 1.09478 & 1.13369 \\
\hline 0.8 & 1 & 1.00224 & 1.00901 & 1.02050 & 1.03705 & 1.05916 & 1.08755 & 1.13240 \\
\hline 0.9 & 1 & 1.00211 & 1.00848 & 1.01929 & 1.03484 & 1.05557 & 1.08215 & 1.11546 \\
\hline 1.0 & 1 & 1.00200 & 1.00807 & 1.01835 & 1.03312 & 1.05279 & 1.07797 & 1.10946 \\
\hline
\end{tabular}

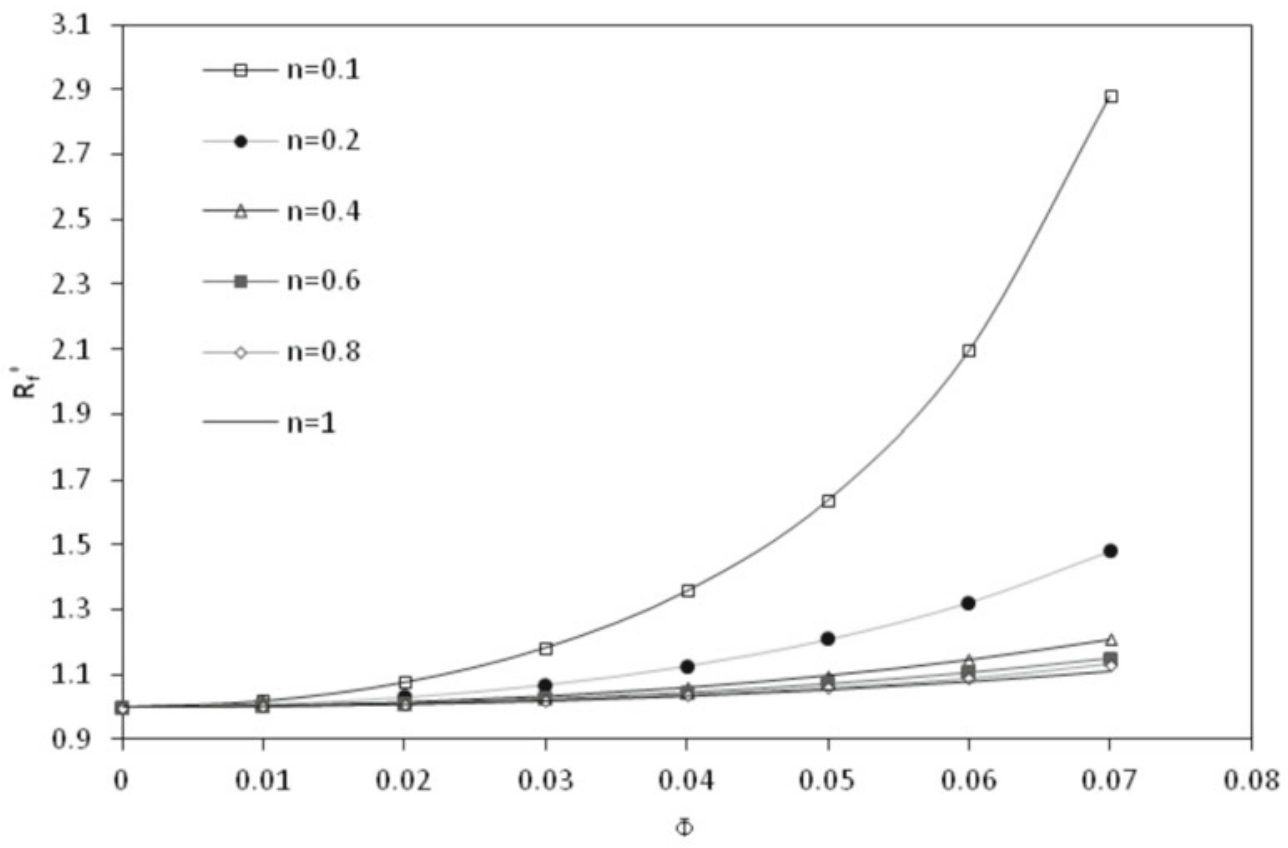

Figure 3. Normalized frictional resistance v/s Relative Roughness for pseudo plastic fluids 
Table 2. Relative roughness, $\varphi \mathrm{v} / \mathrm{s}$ power law index, $\mathrm{n}>1 \mathrm{v} / \mathrm{s}$ normalized frictional resistance, $R_{f}^{*}$

\begin{tabular}{|c|c|c|c|c|c|c|c|c|c|c|}
\hline$\phi$ & 0 & 0.010 & 0.020 & 0.030 & 0.040 & 0.050 & 0.060 & 0.070 & 0.080 & 0.090 \\
\hline $\mathrm{n}$ & $R_{f}{ }^{*}$ & $R_{f}{ }^{*}$ & $R_{f}{ }^{*}$ & $R_{f}{ }^{*}$ & $R_{f}{ }^{*}$ & $R_{f}{ }^{*}$ & $R_{f}{ }^{*}$ & $R_{f}{ }^{*}$ & $R_{f}{ }^{*}$ & $R_{f}{ }^{*}$ \\
\hline 20 & 1 & 1.00124 & 1.00497 & 1.01127 & 1.02026 & 1.03212 & 1.04710 & 1.06553 & 1.08789 & 1.11478 \\
\hline 10 & 1 & 1.00127 & 1.00512 & 1.01160 & 1.02086 & 1.03307 & 1.04851 & 1.06753 & 1.09061 & 1.11842 \\
\hline 9 & 1 & 1.00128 & 1.00515 & 1.01168 & 1.02099 & 1.03329 & 1.04883 & 1.06798 & 1.09123 & 1.11924 \\
\hline 8 & 1 & 1.00129 & 1.00519 & 1.01177 & 1.02116 & 1.03356 & 1.04923 & 1.06854 & 1.09199 & 1.12027 \\
\hline 7 & 1 & 1.00130 & 1.00524 & 1.01189 & 1.02138 & 1.03390 & 1.04974 & 1.06927 & 1.09299 & 1.12159 \\
\hline 6 & 1 & 1.00132 & 1.00531 & 1.01205 & 1.02167 & 1.03437 & 1.05043 & 1.07025 & 1.09432 & 1.12338 \\
\hline 5 & 1 & 1.00135 & 1.00541 & 1.01227 & 1.02208 & 1.03502 & 1.05141 & 1.07163 & 1.09621 & 1.12590 \\
\hline 4 & 1 & 1.00138 & 1.00556 & 1.01262 & 1.02270 & 1.03602 & 1.05289 & 1.07373 & 1.09909 & 1.12975 \\
\hline 3 & 1 & 1.00145 & 1.00582 & 1.01320 & 1.02376 & 1.03772 & 1.05542 & 1.07730 & 1.10399 & 1.13632 \\
\hline 2 & 1 & 1.00158 & 1.00635 & 1.01441 & 1.02595 & 1.04123 & 1.06066 & 1.08474 & 1.11421 & 1.15007 \\
\hline 1 & 1 & 1.00200 & 1.00807 & 1.01835 & 1.03312 & 1.05279 & 1.07797 & 1.10946 & 1.14843 & 1.20000 \\
\hline
\end{tabular}

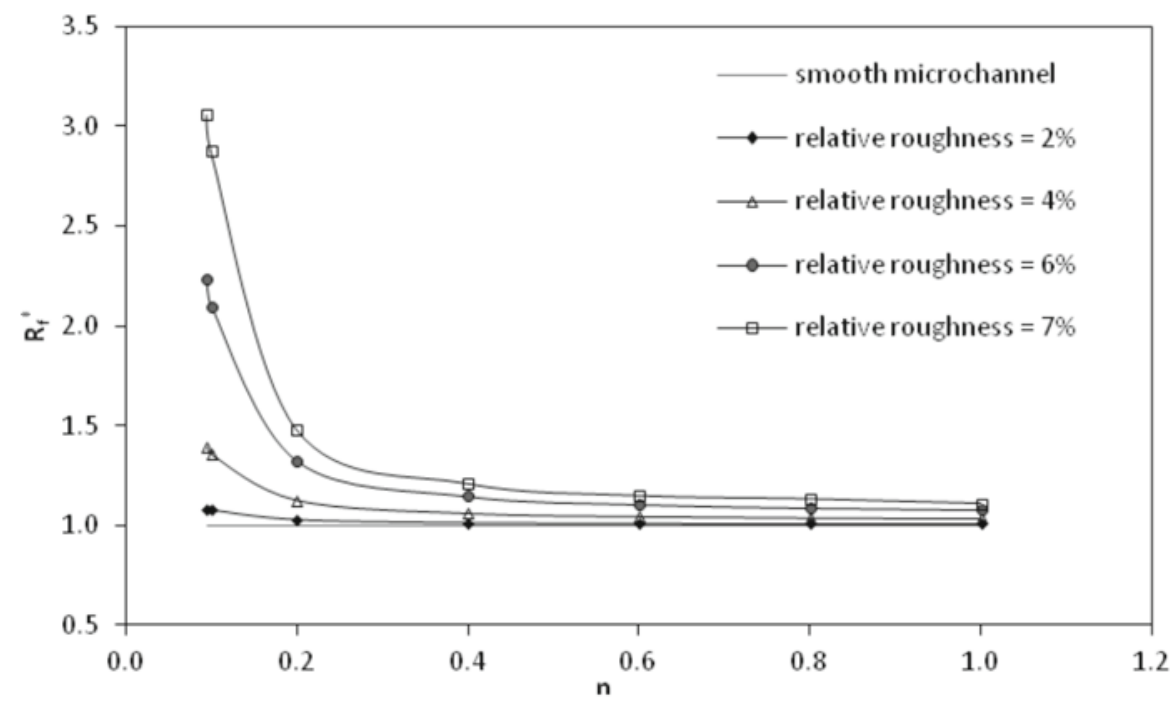

Figure 4. Normalized frictional resistance v/s flow behavior index for pseudo plastic fluids

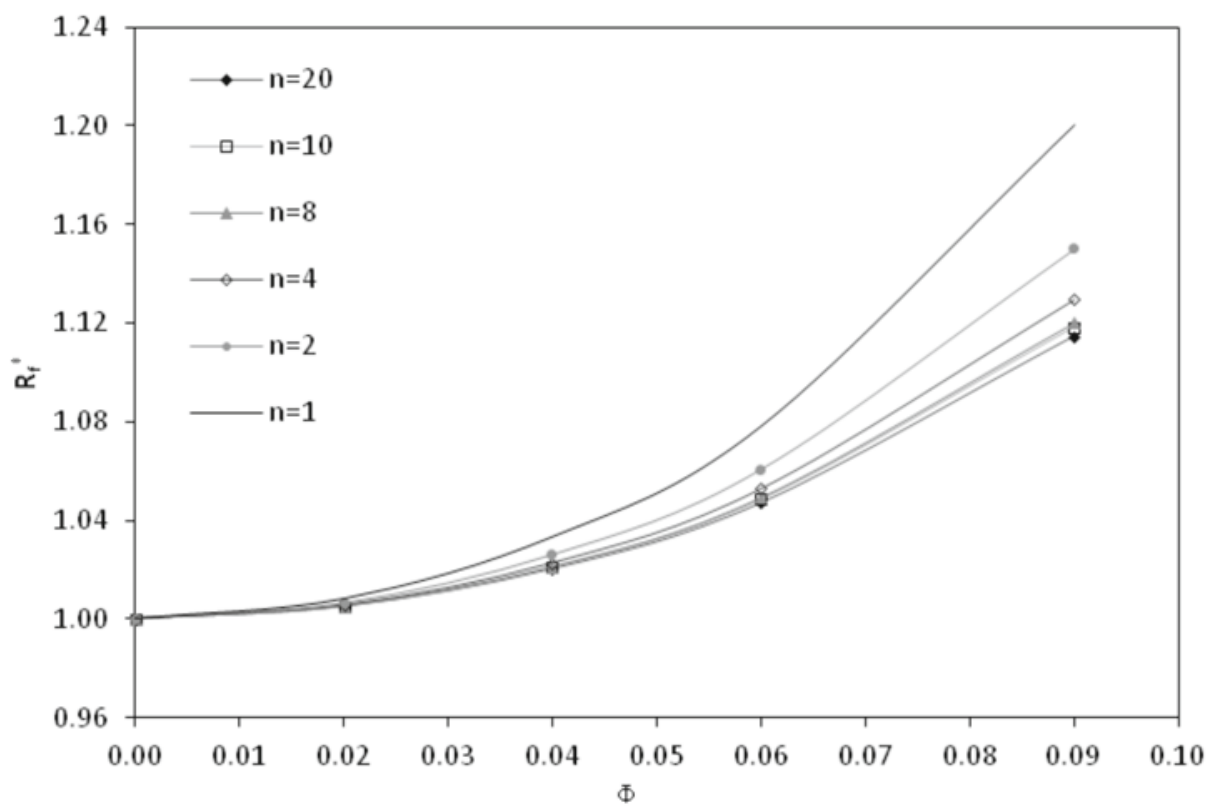

Figure 5. Normalized frictional resistance v/s Relative Roughness for dilatant fluids

$4.6 \%, 5.4 \%, 8.2 \%$ and $11.8 \%$ for the four stainless steel channels of diameter equal to $300,260,170$ and $120 \mu \mathrm{m}$ respectively. The Reynolds number range in the experiments performed by Tang et al. ${ }^{\mathbf{1 4}}$ for various channel diameters is shown in Table 3 . The experimental results reported by them ${ }^{14}$, showed large deviation from the theoretically predicted values of mass flow rates obtained from equation (4), which does not take into account the effect of surface roughness on the flow in
Table 3. Reynolds number range in the experiments performed by ${ }^{14}$ for various channel diameters

\begin{tabular}{|l|c|}
\hline Channel Diameter & Reynolds number range \\
\hline $120 \mu \mathrm{m}$ & $2<\operatorname{Re}<124$ \\
\hline $170 \mu \mathrm{m}$ & $6<\operatorname{Re}<684$ \\
\hline $260 \mu \mathrm{m}$ & $3<\operatorname{Re}<2275$ \\
\hline $300 \mu \mathrm{m}$ & $202<\operatorname{Re}<2284$ \\
\hline
\end{tabular}


the microchannels. They predicted that the obviously reduced mass flow rate or the increased friction factors for PAM was probably caused by the so called electroviscous effect on liquid flow in microchannels. This effect is more pronounce in shear thinning liquid flow. They did also, however hint the effect of roughness in decreasing the mass flow rate. Thus both effects (i.e. the electroviscous effect combined with the effect of surface roughness), are responsible for decreasing the mass flow rate of PAM in the channel. In Fig. 7-10 and Table 4 below, we have indicated the effect of roughness on the flow of PAM in the microchannels. The values of

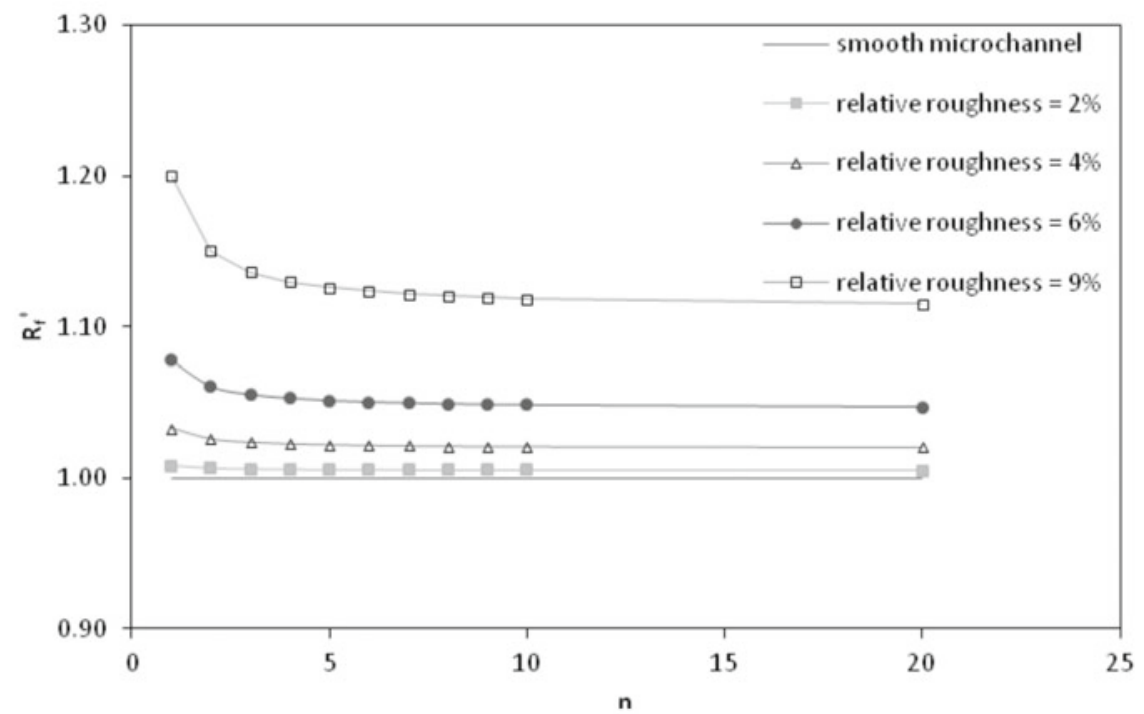

Figure 6. Normalized frictional resistance v/s flow behavior index for dilatant fluids

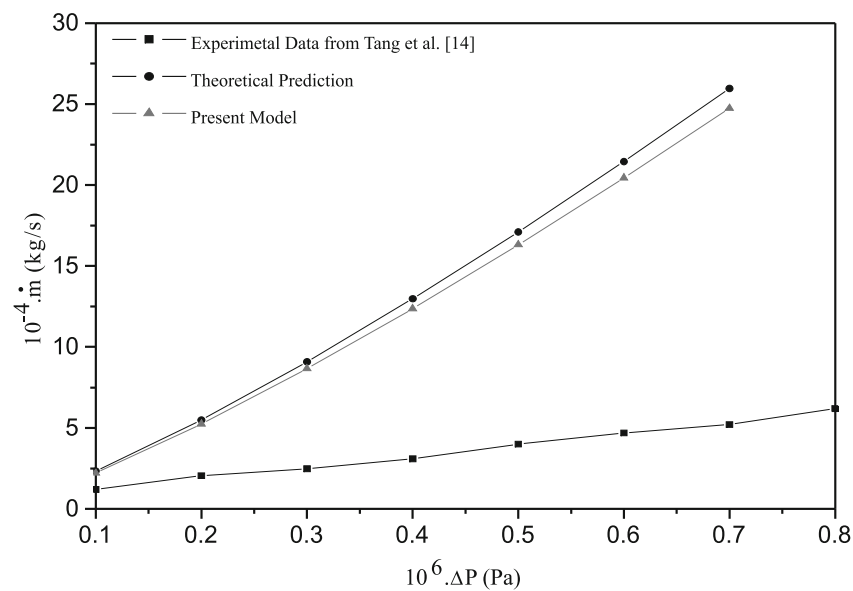

Figure 7. Comparison of the present model to theoretical prediction and the experimental values given by Tang et al. ${ }^{14}$ for PAM flowing in microchannel having $\varphi=$ $4.6 \%$ and $\mathrm{D}=300 \mu \mathrm{m}$

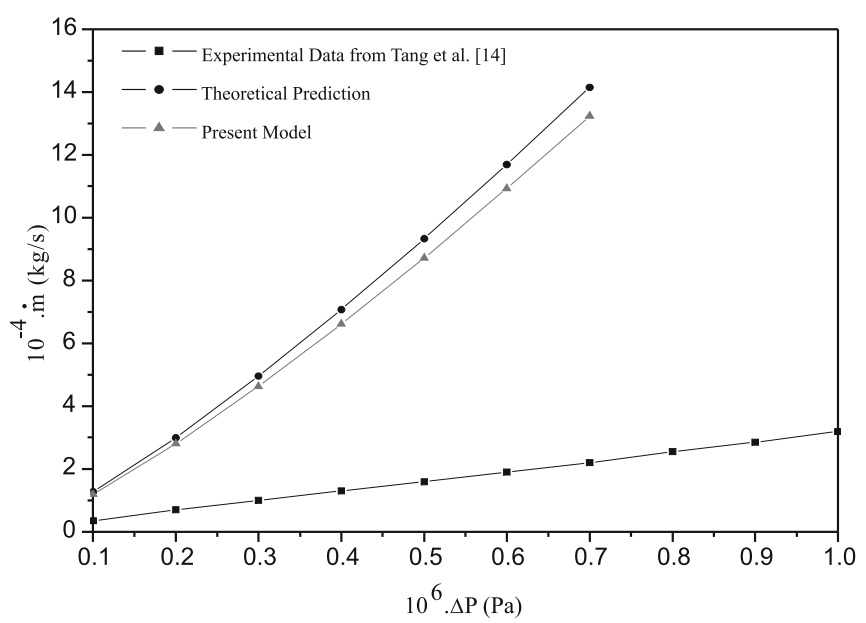

Figure 8. Comparison of the present model to theoretical prediction and the experimental values given by Tang et al. ${ }^{14}$ for PAM flowing in microchannel having $\varphi=$ $5.4 \%$ and $\mathrm{D}=260 \mu \mathrm{m}$

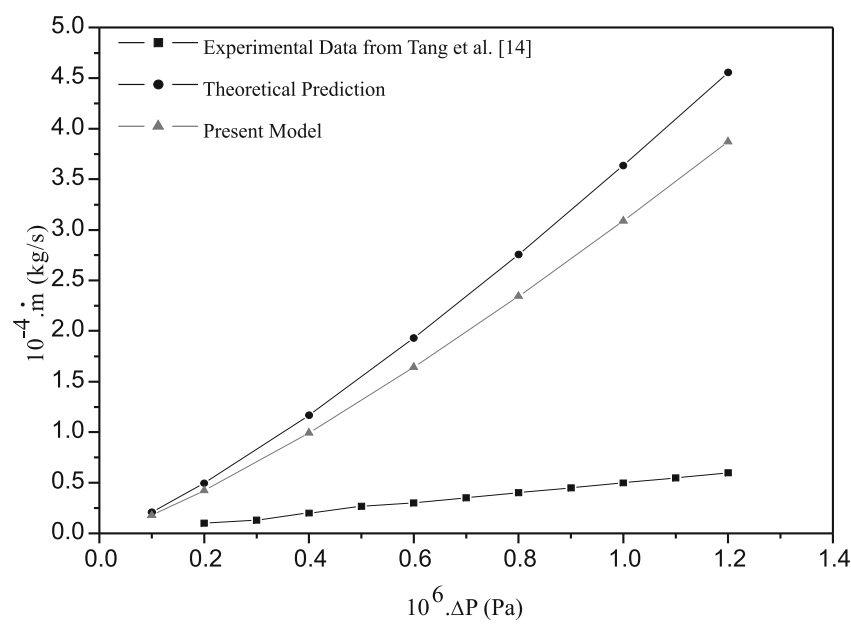

Figure 9. Comparison of the present model to theoretical prediction and the experimental values given by Tang et al. ${ }^{14}$ for PAM flowing in microchannel having $\varphi=$ $8.2 \%$ and $\mathrm{D}=170 \mu \mathrm{m}$

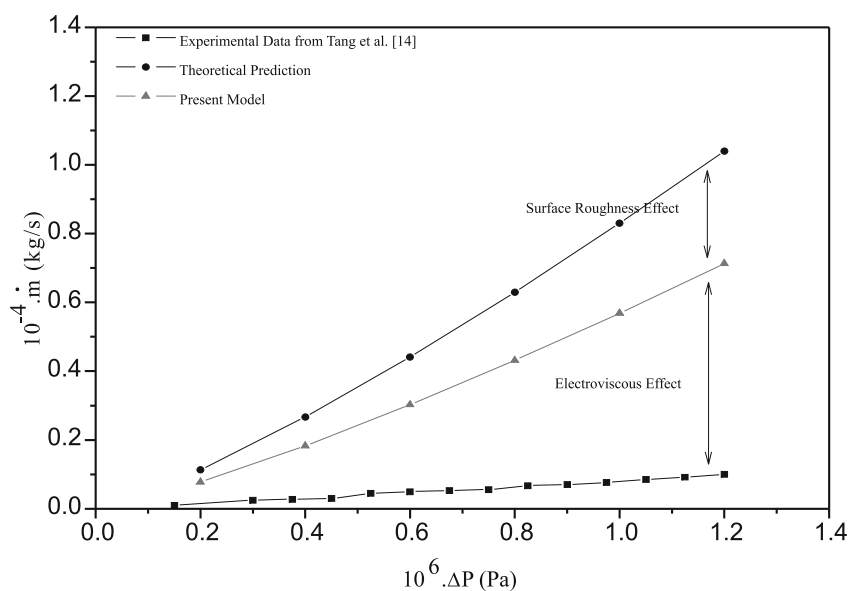

Figure 10. Comparison of the present model to theoretical prediction and the experimental values given by Tang et al. ${ }^{14}$ for PAM flowing in microchannel having $\varphi=11.8 \%$ and $\mathrm{D}=120 \mu \mathrm{m}$ 
Table 4. Comparison of the present model to theoretical prediction and the experimental values given by Tang et al. ${ }^{\mathbf{1 4}}$ for flow of PAM in microchannels with varying surface roughness and diameters

\begin{tabular}{|c|c|c|c|}
\hline $\begin{array}{c}10^{-6}(\Delta P) \\
{[\mathrm{Pa}]}\end{array}$ & $\begin{array}{l}\text { Theoretical prediction, } \\
\qquad 10^{-4}(\dot{m}) \text { [kg/s] }\end{array}$ & Present model, $10^{-4}(\dot{m})[\mathrm{kg} / \mathrm{s}]$ & $\begin{array}{l}\text { Experimental Values* from } \\
{[14], 10^{-4}(\dot{m})[\mathrm{kg} / \mathrm{s}]}\end{array}$ \\
\hline \multicolumn{4}{|c|}{$\phi=11.8 \%$ and $D=120 \mu \mathrm{m}$} \\
\hline 0.2 & 0.113113 & 0.077475 & 0.014 \\
\hline 0.4 & 0.266930 & 0.182829 & 0.030 \\
\hline 0.6 & 0.441084 & 0.302112 & 0.048 \\
\hline 0.8 & 0.629915 & 0.431449 & 0.063 \\
\hline 1.0 & 0.830471 & 0.568815 & 0.079 \\
\hline 1.2 & 1.040890 & 0.712940 & 0.100 \\
\hline \multicolumn{4}{|c|}{$\phi=8.2 \%$ and $D=170 \mu \mathrm{m}$} \\
\hline 0.1 & 0.20980 & 0.178278 & 0.04 \\
\hline 0.2 & 0.49510 & 0.420711 & 0.10 \\
\hline 0.4 & 1.16836 & 0.992816 & 0.20 \\
\hline 0.6 & 1.93063 & 1.640560 & 0.30 \\
\hline 0.8 & 2.75715 & 2.342900 & 0.40 \\
\hline 1.0 & 3.63498 & 3.088840 & 0.50 \\
\hline 1.2 & 4.55600 & 3.871480 & 0.60 \\
\hline \multicolumn{4}{|c|}{$\phi=5.4 \%$ and $D=260 \mu \mathrm{m}$} \\
\hline 0.1 & 1.27042 & 1.18802 & 0.35 \\
\hline 0.2 & 2.99801 & 2.80356 & 0.70 \\
\hline 0.3 & 4.95401 & 4.63269 & 1.00 \\
\hline 0.4 & 7.07486 & 6.61598 & 1.30 \\
\hline 0.5 & 9.32739 & 8.72241 & 1.60 \\
\hline 0.6 & 11.6907 & 10.9325 & 1.90 \\
\hline 0.7 & 14.1504 & 13.2326 & 2.20 \\
\hline \multicolumn{4}{|c|}{$\phi=4.6 \%$ and $D=300 \mu \mathrm{m}$} \\
\hline 0.1 & 2.33010 & 2.22050 & 1.20 \\
\hline 0.2 & 5.49869 & 5.24004 & 2.05 \\
\hline 0.3 & 9.08622 & 8.65882 & 2.48 \\
\hline 0.4 & 12.9761 & 12.3657 & 3.10 \\
\hline 0.5 & 17.1075 & 16.3028 & 4.00 \\
\hline 0.6 & 21.4421 & 20.4335 & 4.70 \\
\hline 0.7 & 25.9534 & 24.7326 & 5.20 \\
\hline
\end{tabular}

* Thease are approximate values from graphs given in [14] and are only used to show a comparison.

the mass flow rate derived by the present model show a significant difference of around $4.7 \%, 6.49 \%, 15.02 \%$ and $31.5 \%$ for channels having diameters 300, 260, 170 and $120 \mu \mathrm{m}$ respectively from the theoretical predictions by equation (4) which does not take into account the effect of surface roughness. The difference in the values presented by our present model incorporating roughness and the theoretical predictions as given by equation (4), assuming smooth microchannel can be attributed to the effect of surface roughness on the flow of fluid in channel while the difference between the values presented by our model and the experimental values of Tang et al. ${ }^{\mathbf{1 4}}$ can now be linked to the so called electroviscous effect on the flow of non-Newtonian fluids in microchannels. It can be seen that as the channel diameter decreases the effect of channel roughness becomes more pronounced as seen from Table 4 and Fig. 10. It can also be observed from Fig.10, that the effect of surface roughness is as equally crucial as the electroviscous effect in the flow of non-Newtonian liquid in circular microchannel.

\section{CONCLUSION}

In the present model for the flow of the non-Newtonian liquid in a rough circular microchannel, a randomly distributed isotropic Gaussian roughness is taken. The flow behavior index is varied from 0.095 to 20 and the relative surface roughness has been varied up to $7 \%$ for the pseudo plastic fluids and up to $9 \%$ for dilatant fluids. For further increase in the relative roughness, an extrapolation of the table values for a particular flow behavior index can be done. We observe that as the relative roughness increases the normalized frictional resistance increases for a particular flow behavior index from 0.095 to 20 . For the pseudo plastic fluids on increasing the flow behavior index from 0.095 to 1 , it is seen that the normalized frictional resistance decreases for a particular relative roughness value. For dilatant fluids on increasing the flow behavior index for a certain relative roughness value the normalized frictional resistance decreases and reaches its minimum value as $n$, approaches infinity. By comparison of the present model with the theoretical prediction and experimental results of Tang et al. ${ }^{\mathbf{1 4}}$, it is observed that surface roughness also plays an important role as does the electroviscous forces as observed from Fig. 10. Thus, it can be safely said that the surface roughness plays a crucial role in the flow of non-Newtonian liquid fluids in circular microchannel. However, there still more scope for experimentation on flow of non-Newtonian liquid in a rough circular microchannel to arrive at a final conclusion. 


\section{NOMENCLATURE}

D - channel diameter, $m$

$f$ - Fanning friction factor

$\mathrm{k}$ - flow consistency index

L - length of the channel, $\mathrm{m}$

$\dot{m}$ - mass flow rate, $\mathrm{kg} / \mathrm{s}$

$\mathrm{n}$ - flow behavior index

$\mathrm{R}$ - channel radius, $\mathrm{m}$

$\mathrm{Re}$ - Reynolds number

$R_{f}$ - frictional resistance, $\mathrm{m}^{-1} \mathrm{~s}^{-1}$

$R_{f}^{*}$ - normalized frictional resistance

$v$ - velocity, $\mathrm{m} / \mathrm{s}$

$\bar{v}$ - average velocity, $\mathrm{m} / \mathrm{s}$

\section{Greek}

$\varphi$ - relative roughness

$\sigma$ - roughness standard deviation, $\mathrm{m}$

$\Delta P$ - pressure gradient, $\mathrm{Pa}$

$\varphi, \omega-$ random variables, $\mathrm{m}$

$\rho$ - fluid density, $\mathrm{kg} / \mathrm{m}^{3}$

$\mu \quad$ - viscosity, $\mathrm{kg} / \mathrm{m}$.s

$\tau$ - shear force, $\mathrm{kg} / \mathrm{m} . \mathrm{s}^{2}$

$\theta$ - angle, radians

\section{LITERATURE CITED}

1. Obot, N.T. (2002). Toward a better understanding of friction and heat/mass transfer in microchannels - a literature review. Microscale Thermophysical Engineering. 6 (3), 155-173. DOI: 10.1080/10893950290053295.

2. Tuckerman, D.B. \& Pease, R.F.W. (1981). High-performance heat sinking for VLSI. IEEE Electron Device Letters. 2 (5), 126-129. DOI: 10.1109/EDL.1981.25367.

3. Urbanek, W., Zemel, J.N. \& Bau, H.H. (1993). An investigation of the temperature dependence of Poiseuille numbers in microchannel flow. J. of Micromechanics and Microengineering. 3 (4), 206-208. DOI: 10.1088/09601317/3/4/009.

4. Mala, G.M. \& Li, D. (1999). Flow characteristics of water in microtubes. Int. J. of Heat and Fluid Flow. 20 (2), 142-148. DOI: 10.1016/S0142-727X(98)10043-7.

5. Celata, G.P., Cumo, M., Guglielmi, M. \& Zummo, G. (2002). Experimental investigation of hydraulic and single phase heat transfer in $0.130 \mathrm{~mm}$ capillary tube. Microscale Thermophysical Engineering. 6 (2), 85-97. DOI: $10.1080 / 10893950290053231$.

6. Brutin, D. \& Tadrist, L. (2003). Experimental friction factor of a liquid flow in microtubes. Physics of Fluids. 15 (3), 653-661. DOI: 10.1063/1.1538612.

7. Li, Z.X., Du, D.X. \& Guo, Z.Y. (2003). Experimental study on flow characteristics of liquids in circular microtubes. Microscale Thermophysical Engineering. 7 (3), 253-265. DOI: 10.1080/10893950390219083.

8. Phares, D.J. \& Smedley, G.T. (2004). A study of laminar flow of polar liquids through circular microtubes. Physics of Fluids. 16 (5), 1267-1272. DOI: 10.1063/1.1691395.

9. Kandlikar, S.G., Joshi, S. \& Tian, S. (2003). Effect of Surface Roughness on Heat Transfer and Fluid Flow Characteristics at low Reynolds Number in Small Diameter Tubes. Heat Transfer Engineering. 24 (3), 4-16. DOI: $10.1080 / 01457630390149260$.
10. Tang, G.H., Li, Z., He, V. \& Tao, W.Q. (2007). Experimental Study of Compressibility, Roughness and Rarefaction Influences on Microchannel Flow. Int. J. of Heat and Mass Transfer. 50 (11-12), 2282-2295. DOI: 10.1016/j.ijheatmasstransfer.2006.10.034.

11. Ghajar, A.J., Tang, C.C. \& Cook, W.L. (2010). Experimental Investigation of Friction Factor in the Transition Region for Water Flow in Minitubes and Microtubes. Heat Transfer Engineering. 31 (8), 646-657. DOI: 10.1080/01457630903466613.

12. Engin, T., Dogruer, U., Evrensel, C., Heavin, S. \& Gordaninejad, F. (2004). Effect of Wall Roughness on Laminar Flow of Bingham Plastic Fluids through Microtubes. ASME J. of Fluids Engineering. 126, 880-883. DOI: $10.1115 / 1.1792252$.

13. Bahrami, M., Yovanovich, M.M. \& Culham, J.R. (2005). Pressure Drop of Fully Developed, Laminar Flow in Rough Microtubes, Proceedings of MICROMINI, ASME $3^{\text {rd }}$ International Conference on Microchannels and Minichannels, 13-15 June 2005 (pp. 259-268).Toronto, Ontorio, Canada. DOI: 10.1115/ICMM200-75108.

14. Tang, G.H., Lu, Y.B., Zhang, S.X., Wang, F.F. \& Tao, W.Q. (2012). Experimental investigation of non-Newtonian liquid fluid flow in microchannels. J. of Non-Newtonian Fluid Mechanics. 173-174, 21-29. DOI: 10.1016/j.jnnfm.2012.02.001.

15. McCabe, W.L., Smith, J.C. \& Harriott, P. (1993). Unit Operations of Chemical Engineering ( $5^{\text {th }}$ ed.). Chemical And Petroleum Engineering Series, McGraw-Hill International Editions. 